\title{
Disability, Urban Health Equity, and the Coronavirus Pandemic: Promoting Cities for All
}

\author{
Victor Santiago Pineda $\cdot$ Jason Corburn
}

(C) The New York Academy of Medicine 2020, corrected publication 2021

\begin{abstract}
Persons with disabilities (PWDs) living in cities during the COVID-19 pandemic response may be four times more likely to be injured or die than non-disabled persons, not because of their "vulnerable" position but because urban health policy, planning and practice has not considered their needs. In this article, the adverse health impacts on PWDs during the COVID-19 pandemic reveals the "everyday emergencies" in cities for PWDs and that these can be avoided through more inclusive community planning, a wholeof-government commitment to equal access, and implementation of universal design strategies. Importantly, COVID-19 can place PWDs at a higher risk of infection since some may already have compromised immune and respiratory systems and policy responses, such as social distancing, can lead to life-threatening disruptions in care for those that rely on home heath or personal assistants. Living in cities may already present healthdamaging challenges for PWDs, such as through lack of access to services and employment, physical barriers on streets and transportation, and smart-city technologies that are not made universally accessible. We suggest
\end{abstract}

\footnotetext{
V. S. Pineda

Department of City \& Regional Planning, UC Berkeley, Berkeley, CA, USA

e-mail: victor@worldenabled.org

URL: http://worldenabled.org/

J. Corburn $(\triangle)$

School of Public Health \& City \& Regional Planning, UC

Berkeley, Berkeley, CA, USA

e-mail: jcorburn@berkeley.edu
}

that the current pandemic be viewed as an opportunity for significant urban health reforms on the scale of the sanitary and governance reforms that followed ninetieth century urban epidemics. This perspective offers insights for ensuring the twenty-first century response to COVID-19 focuses on promoting more inclusive and healthy cities for all.

Keywords COVID-19 pandemic · Climate change · Persons with disabilities $\cdot$ Health equity

\section{Perspective}

During the COVID-19 pandemic, as well as other recent emergencies brought on by climate change and other disasters, persons with disabilities (PWDs) [1] living in cities may be four times more likely to be injured or die than non-disabled persons, not because of their "vulnerable" position but because urban health policy, planning, and practice have not considered their needs [2]. We suggest in this perspective that the adverse health impacts on PWDs during the COVID-19 pandemic reveal the "everyday emergencies" in cities for PWDs and that these can be avoided through more inclusive community planning, a whole-of-government commitment to equal access, and implementation of universal design strategies [3]. Importantly, COVID-19 can place PWDs at a higher risk of infection since some may already have compromised immune and respiratory systems, and policy responses, such as social distancing, can lead to life- 
threatening disruptions in care for those that rely on home health or personal assistants [4]. Living in cities may already present health-damaging challenges for PWDs, such as lack of access to services and employment, physical barriers on streets and transportation, and smart city technologies that are not made universally accessible. We suggest that the current pandemic be viewed as an opportunity for significant urban health reforms on the scale of the sanitary and governance reforms that followed the nineteenth-century urban epidemics. This perspective offers insights for ensuring the twenty-first-century response to COVID-19 focuses on promoting more inclusive and healthy cities for all.

\section{Disability, Emergencies, and the Urban Health Challenge}

The WHO and World Bank reported that "more than one billion people in the world live with some form of disability, of whom nearly 200 million experience considerable difficulties in functioning,", and by 2050, 940 million people in cities may be living with a disability [5]. Disability can impact key social determinants of health. For example, in the USA, $62 \%$ of PWDs (including physical, intellectual, and developmental; sensory; and other disability categories) are unemployed, $27 \%$ live below the poverty line [6], and over $45 \%$ rated their health as "fair or poor" in 2018, making PWDs an often unrecognized health disparity population [7]. Urban health equity for PWDs means recognizing the immediate, acute care needs that they face but also reversing the social, physical, and often place-based determinants of poor health that have gone unaddressed in cities [8].

The WHO states that disability is an intersecting issue of public health, human rights, and development, noting that poverty, combined with the high prevalence of PWDs in low-income countries, makes this a global health and urban development issue [9]. Part of the urban health equity challenge raised by the COVID-19 crisis and acknowledged by the $\mathrm{UN}$ is confronting the all too common medical model of disability, which defines people as disabled due to their impairments or differences [10]. Moving toward urban health equity in cities means implementing the social model of disability in all policies. The social model of disability views impairments as limitations of public policy, not people. For example, in urban health planning, a street intersection without a curb cut that limits a person in a wheelchair from crossing is a limitation and failure of urban design, policy, and planning, not the person. Further, in low-income countries around the world where $50-75 \%$ of the urban population lives in slums or informal settlements, the difficulties of social distancing for those with a disability should not be viewed as an individual challenge but rather a failure of land use, shelter, and infrastructure planning.

Lessons from previous disasters and emergencies offer some guidance for inclusive, urban health planning for the COVID-19 pandemic. A 2006 post-Hurricane Katrina and Rita report by the US National Council on Disabilities (NCD) noted that in New Orleans, "people with disabilities were disproportionately affected by the Hurricanes because their needs were often overlooked or completely disregarded. Their evacuation, shelter, and recovery experiences differed vastly from the experiences of people without disabilities" [11]. A 2010 US Federal Emergency Management Agency (FEMA) report, "Guidance on Planning for Integration of Functional Needs Support Services in General Population Shelters", focused on what emergency managers and planners should do to ensure sheltering services and facilities are accessible, but does not mention how to handle "shelter-in-place" conditions [12]. In the West African Ebola outbreak of 2014, Marais et al. noted the importance of including community knowledge, including that of PWDs, in educating different groups and in preventing transmission [13]. Wars in the Middle East, West and Central Africa, and other regions have left tens of thousands disabled, many of whom migrate to cities seeking care but are then denied access to schools, employment, and face stigma [14]. Armed conflict continues to increase the number of disabled children and has made girls and women especially susceptible to exploitation and infections, including HIV and other diseases [15].

An unaddressed key issue during this pandemic, which also applies to the human rights of PWD, is how to ensure PWDs continue to receive the support required to ensure their well-being, independence, and self-determination when their regular caregivers/ personal assistants are quarantined, fall ill, and/or are unable to continue providing support [16]? In China, there was a case during the COVID-19 quarantine where a disabled teenager died after being left at home for 6 days without care, while his relatives were quarantined [17]. In Italy and other European countries, there were few messages communicated in accessible formats, and 
no specific measures were taken early in the crises for PWDs [18]. An early lesson is that cities must ensure that all public health messaging, technologies, and communications are accessible to all. For instance, during COVID-19, very few public announcements include sign language interpretation, and the ubiquity of face masks can further frustrate the ability of those who rely on lip-reading to understand and communicate.

The livelihoods of persons with disabilities are also at serious risk due to the economic downturn brought about by the pandemic. Yet, PWDs have not been included in economic responses to the COVID-19 pandemic nor involved in planning to prevent future crises [19]. As the UN Special Rapporteur on the rights of persons with disabilities, Catalina Devandas, noted on 20 March 2020: "People with disabilities feel they have been left behind. Containment measures, such as social distancing and self-isolation, may be impossible for those who rely on the support of others to eat, dress and bathe." We suggest that people with disabilities bring a unique expertise to framing and implementing public health activities [20].

\section{The Cities for All Response to Epidemics and Health Equity}

Below we offer some brief recommendations for how the COVID-19 pandemic response can best support PWDs and why these practices will also ensure cities are made more inclusive and healthier for all. Our recommendations are grounded in international law. For example, the Standard Rules on the Equalization of Opportunity for Persons with Disabilities (1994) (A/RES/48/96) identify "accessibility" of the physical environment and of information and communication as two "target areas" to ensure equalization of opportunities. The Article 25 of the UN Convention on the Rights of Persons with Disabilities (CRPD) reinforces the right of PWDs to attain the highest standard of health and health care, without discrimination [21]. Cities have been slow to comply with these directives, as they have "left behind" those with physical impairments by not adopting universal design principles in urban development, by ignoring the needs of PWDs in the adoption of new, smart city technologies, and through other forms of physical and social exclusion [22].

We offer the following recommendations for inclusive cities in response to COVID-19:

\section{(1) Accessible Information Access}

Cities must disseminate public information in accessible formats, including sign language and real-time captioning at all press conferences and public service announcements. Public health and wellness information must be in audio, Braille, E-pub, and easy-to-understand formats; use captioning; relay services; text messages; and always ensure digital technologies are in compliance with $\mathrm{W} 3 \mathrm{C}$ accessibility standards [23]. In the crafting of COVID-19 messages, cities should also take extra care in ensuring that all public communications do not discriminate against or reinforce harmful stereotypes of any population group, including persons with disabilities.

\section{(2) Inclusive decision-making}

PWDs and disabled persons' organizations (DPOs) must be at the center of the program and policy decisions and implementation. This can ensure that the needs of persons with diverse disabilities are adequately met and their rights and dignity respectfully upheld. COVID-19 responses should be inclusive by prioritizing the principles of Universal Design and Access as well as the Convention on the Rights of Persons with Disabilities. Cities should continually consult with DPOs and use participatory approaches in policy design and implementation. Indeed, persons with disabilities hold a privileged vantage point in understanding and dealing with crises and are a special asset in the current pandemic. Therefore, governments and local authorities should establish Pandemic Responses Task Forces that include PWDs to make sure that the latter are consulted, and accessibility, inclusivity, and universal design are mainstreamed into risk reduction responses.

\section{(3) Accessibility through continuity of care and social supports}

Cities should ensure that persons with disabilities have continued access to essential services, including healthcare and personal assistants. During any closure or minimization of services, PWDs must be supported to meet their daily living requirements, including access to food (as needed with specific dietary requirements), housing, healthcare, and in-home school and community supports [24]. PWDs must be allowed to make their own choices in all aspects of their COVID-19 
contingency plans when their services and supports may be interrupted. This includes choosing who provides assistance when related to their bodily functions, daily life, and individual needs [25]. Personal assistance service providers should be given paid sick time to encourage providers to practice social distancing, but this also requires increased funding for Independent Living Centers and developmental disability service providers to ensure there are emergency back-up assistants. Further, there is an opportunity for cities to invest in existing DPOs by providing them financial support to offer culturally competent continuity of care training and service delivery, especially when there are human resource shortages.

\section{(4) Economic Supports}

PWDs in many cities are living in poverty, may be informal day laborers or are homeless, and expenditures used to arrest the COVID-19 pandemic must also be used to improve the immediate and long-term economic status of PWDs. Economic hardship is furthered when PWDs are forced to pay more for essential life supports, such as utilities, transportation, and food. A 2019 study in the UK by John et al., called the "Disability Price Tag," found that PWDs spent about 700 USD more a month than others, due to higher costs for transportation, utilities, care, and such things as accessible hotel rooms. These costs make it much harder for PWDs to build savings and plan for the future and make them extremely vulnerable to economic shocks, like the current coronavirus pandemic [26]. One policy response could be eliminating any restrictions governments may have on hiring family members to ensure continuity of care for PWDs.

\section{(5) Non-discrimination}

PWDs are frequently subject to discrimination and stigma, which can impact their access to care, employment, and other life supports. Cities should adopt more strict anti-discrimination and labor protection laws for PWDs and strengthen enforcement of such laws during this crisis to safeguard against unfair or discriminatory dismissal from work and/or needed care services. PWDs may also be receiving disability benefits, and these must not only continue on time but also may need to be enhanced to buffer the increased costs of living for PWDs stemming from the pandemic, such as the extra costs of home deliveries and/or hiring of private support due to the suspension of public services.

\section{Toward Disability Justice and Global Healthy Cities for All}

We have offered a few recommendations to ensure persons with disabilities living in cities are not disproportionately harmed during the COVID-19 crisis. Clearly, many of these suggestions should continue beyond the crisis and form an "urban disability justice" strategy, which can address systemic ableism in urban health research, policy, and planning [27]. The COVID-19 crisis can highlight and hopefully reveal policies to reverse the everyday crises and structural exclusion that PWDs face in cities [28]. The global pandemic must be viewed by global urban health advocates much like the urban epidemics of the nineteenth century, where urban sanitary and governance reforms helped improve population health [29]. However, some responses to the urban epidemics of the nineteenth and early twentieth century enhanced exclusion and segregation in cities, while others challenged colonialist, racist, and discriminatory urban health practices [30]. The COVID-19 crisis presents urban health practitioners with an opportunity to maintain the status quo, perpetuate even greater spatial segregation and exclusion, or to offer a vision for (re)building our cities to be more inclusive and healthier for all.

Acknowledgements We thank the International Disability Alliance and all those participating in the Cities for All, Global Compact on Inclusive and Accessible Cities, for helpful input. Our recommendations benefitted from input by participants in the webinar entitled "Equity and Access in Times of Pandemic," part of the Cities for All Campaign, https://www.cities4all.org.

\section{References}

1. World Bank. International classification of functioning, disability and health. World Health Organization, Geneva. 2001. ISBN 924154542 9. https://www.who. int/classifications/icf/en/. Accessed 30 March 2020.

2. Izutsu, T. Disability-inclusive disaster risk reduction and humanitarian action: an urgent global imperative. 29 November 2019. Paper presented at United Nations World Conference on disaster risk reduction and the progress thereafter. https://www.un.org/development/desa/disabilities/wp- 
content/uploads/sites/15/2020/03/Final-Disabilityinclusive-disaster.pdf. Accessed 1 April 2020

3. Sendai Statement to Promote Disability-inclusive Disaster Risk Reduction for Resilient, Inclusive and Equitable Societies in Asia and the Pacific. 2014. Published jointly by The Nippon Foundation, Rehabilitation International \& the United Nations Economic and Social Commission for Asia and the Pacific (ESCAP). https://www.preventionweb. net/english/professional/policies/v.php?id=40420. Accessed 23 March 2020.

4. UN News. Preventing discrimination against people with disabilities in COVID-19 response. https://news.un. org/en/story/2020/03/1059762. Accessed 19 March 2020.

5. World Health Organization. WHO global disability action plan 2014-2021: Better health for all people with disability. 2015. Geneva: WHO. ISBN 9789241509619. https://www. who.int/disabilities/actionplan/en/. Accessed 19 March 2020.

6. Institute on Disability. 2019 Annual report on people with disabilities in America. 2019. University of New Hampshire: Institute on Disability. https://disabilitycompendium. org/sites/default/files/user-uploads/2019\%20Annual\%20 Report\%20\%2D\%2D-\%20FINAL\%20ALL.pdf. Accessed 19 March 2020.

7. Krahn GL, Walker DK, Correa-de-Araujo R. Persons with disabilities as an unrecognized health disparity population. AJPH. 2015;105:S198-206. https://doi.org/10.2105 /AJPH.2014.302182.

8. Videlefsky AS, et al. Addressing health disparities in adults with developmental disabilities. Ethn Dis. 29(Suppl 2):3558. 13 Jun. 2019. https://doi.org/10.18865/ed.29.S2.355.

9. World Health Organization. World report on disability. Geneva: World Health Organization. 2011. ISBN 978924 156418 2. https://www.who.int/disabilities/world_ report/2011/report.pdf. Accessed 20 March 2020.

10. UN Economic and Social Commission for Asia and the Pacific (ESCAP). Ensuring disability rights and inclusion in the response to COVID-19. 20 March 2020. UN ESAP: Bangkok, Thailand. https://www.unescap. org/resources/policy-brief-covid-19-and-person-disabilities. Accessed 23 March 2020.

11. Powell, R. \& Sheldon, G. The impact of hurricanes Katrina and Rita on people with disabilities: a look back and remaining challenges. National Council on Disability, Washington, D.C. August, 2006. https://www.ncd.gov/rawmedia repository/e89f084e_e132_496c_a5b8_56351dfb3f10.pdf. Accessed 23 March 2006.

12. The Federal Emergency Management Agency's (FEMA). Guidance on planning for integration of functional needs support services in general population shelters. 2010. BCFS health and human services, San Antonio, Texas. https://www.fema.gov/media-librarydata/20130726-183125045-7316/fnss guidance.pdf. Accessed 23 March 2020.

13. Marais F, Minkler M, Gibson N, Mwau B, Mehtar S, Ogunsola F, et al. A community-engaged infection prevention and control approach to Ebola. Health Promot Int. 2016;31(2):440-9. https://doi.org/10.1093/heapro/dav003.

14. Amnesty International. Excluded: Living with Disabilities in Yemen's Armed Conflict. 3 December 2019, Index number: MDE 31/1383/2019. https://www.amnesty.
org/download/Documents/MDE3113832019ENGLISH. PDF. Accessed 24 March 2020.

15. Kadir A, et al. Effects of armed conflict on child health and development: a systematic review. PloS One. 2019;14(1): e0210071. https://doi.org/10.1371/journal.pone.0210071.

16. Kaiser, C. \& Brossard, L. Recommendations for health protection of people with disabilities during outbreaks: lessons learned from the 2019 novel coronavirus. ONG Inclusiva, Chile. 2020. http://onginclusiva. com/onginclusiva/wpcontent/uploads/2020/02 / R E C O M M EN D A T I O N S - F O R - H E A L T H PROTECTION-OF-PEOPLE-WITH-DISABILITIESDURING-OUTBREAKS.pdf. Accessed 24 March 2020.

17. Chen, L. 2020. Left at home for six days: disabled Chinese boy dies after dad and brother are quarantined for coronavirus checks. South China Morning Post. 30 January 2020. https:/www.scmp.com/news/china/society/article/3048208 /left-home-six-days-disabled-chineseboy-dies-after-carerdad-and. Accessed 22 March 2020.

18. Council of Europe. Persons with disabilities must not be left behind in the response to the COVID-19 pandemic. Commissioner for Human Rights. 2 April 2020. https://www.coe.int/en/web/commissioner/-/persons-withdisabilities-must-not-be-left-behind-in-the-response-tothecovid-19-pandemic. Accessed 5 April 2020.

19. UN Human Rights, Office of the High Commission. COVID19: who is protecting the people with disabilities? - UN rights expert. 17 March 2020. UN: Geneva. https:/www.ohchr. org/EN/News Events/Pages/DisplayNews.aspx? NewsID=25725\&LangID=E. Accessed 23 March 2020.

20. UN Economic and Social Commission for Asia and the Pacific (ESCAP). Ensuring disability rights and inclusion in the response to COVID-19. 20 March 2020. UN ESAP: Bangkok, Thailand. https://www.unescap. org/resources/policy-brief-covid-19-and-person-disabilities. Accessed 23 March 2020.

21. World Humanitarian Summit. Charter on inclusion of persons with disabilities in humanitarian action. 2016. http://humanitariandisabilitycharter.org/the-charter/. Accessed 28 March 2020.

22. United Nations Secretariat, Department for Economic and Social Affairs (UNDESA). Good practices of accessible urban development: making urban environment inclusive and fully accessible to all. 21 October 2016. https://www. un.org/disabilities/documents/desa/good_practices_in accessible_urban_development_october2016.pdf. Accessed 22 March 2020 .

23. World Wide Web Consortium. Web Content Accessibility Guidelines (WCAG) 2.1 (WAI). 5 June 2018. https://www. w3.org/TR/WCAG21/. Accessed 20 March 2020.

24. Pulrang A. Five things to know about coronavirus and people with disabilities. Forbes, 8 March 2020. https://www.forbes.com/sites/andrewpulrang/2020/03/08/5things-to-know-about-coronavirus-and-people-withdisabilities/\#44657db31d21. Accessed 20 March 2020.

25. World Institute on Disability. Recommendations for immediate action regarding: the rights $\&$ needs of people with disabilities who use personal assistance services \& supports throughout COVID-19 Planning \& Response. 12 March 2020. Available: https://wid.org/2020/03/12 
/recommendations-for-immediate-covid-19-action/. Accessed 23 March 2020.

26. John, E., Thomas, G., \& Touchet, A. The disability price tag. Scope. February 2019. London, UK. https://www.scope.org. uk/campaigns/extra-costs/disability-price-tag/. Accessed 18 March 2020.

27. Sins Invalid. Skin, tooth, and bone-the basis of movement is our people: a disability justice primer. San Francisco: Sins Invalid; 2016. https://www.sinsinvalid.org/disability-justice-primer.

28. Nakkeeran N, Nakkeeran B. Disability, mental health, sexual orientation and gender identity: understanding health inequity through experience and difference. Health Res
Policy Syst. 2018;16(Suppl 1):97. https://doi.org/10.1186 /s12961-018-0366-1.

29. Duffy, J. The Sanitarians: a history of American public health. Urbana: University of Illinois Press. 1990. ISBN10: 0252062760.

30. Curtin P. Medical knowledge and urban planning in tropical Africa. Am Hist Rev. 1985;90(3):594-613. https://doi. org/10.1086/ahr/90.3.594.

Publisher's Note Springer Nature remains neutral with regard to jurisdictional claims in published maps and institutional affiliations. 